\title{
DISTRIBUIÇÃO ESTACIONAL DA CRIPTOSPORIDIOSE EM BEZERROS DE BELA VISTA-GO
}

\author{
José Roberto Carneiro ", José Divino Lima. ${ }^{* *}$, Nicanor Rodrigues ${ }^{* * *}$
}

\section{RESUMO}

A distribuição estacional da criptosporidiose foi estudada em bezerros oriundos de uma propriedade rural, no município de Bela Vista-Go. Os meses de maior ocorrência do Cryptosporidium em fezes de bezerros, foram: janeiro a maio de 1993, e de dezembro de 1993 a fevereiro de 1994 inclusive. A prevalência global estimada de Cryptosporidium em fezes diarréicas e não diarréicas dos bezerros, foi de $15,81 \%$.

UNITERMOS: Variação sazonal, Cryptosporidium, bezerros.

\section{INTRODUÇÃO}

Os resultados da influência climática na ocorrência do Crytosporidium são discordantes entre os pesquisadores. POHLENZ et al. (1978), ALLEN \& WHITE (1985) não observaram uma variação sazonal na incidência de oocistos de Crytosporidium em fezes de bezerros.

Segundo ARMSTRONG (1987) a sazonalidade na criptosporidiose não foi ainda estabelecida. No entanto, ANGUS (1988) verificou uma maior freqüência de Crytosporidium em bezerros no final do inverno e início da primavera, com um segundo pico no outono. HENRIKSEN (1988) concluiu que em alguns países a doença é mais comum no inverno quando os bezerros, se concentram em instalações que favorecem uma maior concentração de oocistos por área.

O objetivo do trabalho é verificar a distribuição estacional da criptosporidiose em bovinos da microrregião de Goiânia.

\footnotetext{
- Prof. Titular do Depto. de Parasitologia do IPTSP/UFG

- Bolsista do CNPq.

Médico Veterinário IPTSP/UFG

Recebido para publicação em 23/08/95
} 
CARNEIRO JR ; de Bela Vista-Go. Rev. Pat. Trop.24 ( 2 ): $235-241$, jul/dez. 1995

\section{MATERIAL E MÉTODOS}

\section{População estudada}

Para verificar uma possível tendência sazonal, foram examinados quinzenalmente, durante 28 quinzenas, 234 bezerros, sendo 105 machos e 129 fêmeas, na faixa etária de 0 a 30 dias.

Este estudo foi realizado em uma fazenda localizada no município de Bela Vista, a $36 \mathrm{~km}$ de Goiânia-Go. A propriedade foi escolhida pela proximidade de Goiânia, por ocorrerem nascimentos de bezerros durante todo o ano e pela presença de Cryptosporidium previamente comprovada.

Os animais eram mestiços de zebu e holandês, e foram mantidos, logo após o nascimento e até 30 dias, em um galpão cimentado em piquete de grama estrela (Cynodon plectostachyus). Os animais da propriedade são vacinados contra aftosa, carbúnculo sintomático e tratados contra ecto e endoparasitas.

A propriedade escolhida apresentava um manejo semelhante ao das fazendas produtoras de leite da região, incluindo o sistema de 2 ordenhas diárias.

\section{Colheita de fezes e exames de laboratório}

As colheitas de fezes foram realizadas no período de janeiro de 1993 a fevereiro de 1994, sendo as amostras colhidas diretamente do reto dos bezerros em sacos plásticos e encaminhadas ao laboratório do Instituto de Patologia Tropical e Saúde Pública - UFG, onde permaneceram estocadas em geladeira a $4^{\circ} \mathrm{C}$ até o momento de serem examinadas. Para o exame as amostras foram submetidas à flutuação em solução saturada de sacarose (solução de Sheather) e coradas pela técnica de Ziehl Neelsen modificada, por HENRIKSEN \& POHLENZ (1981) e modificação sugerida por ORTOLANI (1988).

\section{RESULTADOS}

A prevalência de Cryptosporidium observada em bezerros de uma propriedade rural no município de Bela Vista - Go foi de $15,81 \%$. Os resultados obtidos nos exames realizados quinzenalmente durante 14 meses são apresentados na TAB. 1

Os maiores percentuais de ocorrência de C. parvum, situaram-se no período de dezembro de 1993 a fevereiro de 1994, (48,88\%), vindo em seguida janeiro de 1993 à maio de 1993 , com $12,87 \%$. As colheitas realizadas no período de junho de 1993 a outubro de 1993 apresentaram uma ausência quase total de animais positivos, sendo registrado apenas um caso positivo, $(4,00 \%)$ na primeira quinzena de julho, (GRAF. 1). Os maiores percentuais de ocorrência de Cryptosporidium no período de
CARNEIRO, J.R ;LIMA, J D, ; RODRIGUES, N. Distribuiç de Bela Vista-Go. Rev. Pat. Trop.24 ( 2 ): $235-241$, jul/dez. 1995

dezembro de 1993 a fevereiro de 1994 foram coincidentes com os maiores índices de precipitação pluvial - 354 a 149,2 mm. (GRAF. 1).

A prevalência de amostras positivas é a seguinte em ordem decrescente: fevereiro de 1994, 69,23\% ; dezembro de 1993, 46,67\%; janeiro de 1994, 35,29\%; março de 1993, 29,41\% ; janeiro de 1993, 28,57\% ; fevereiro de 1993, 27,27\% ; novembro de 1993, 11,11\% ; maio de $1993,5,40 \%$ e abril de $1993,3,45 \%$. (TAB. 1).

Em relação à consistência das fezes no período de novembro de 1993 a fevereiro de 1994 , observou-se uma prevalência de 21 amostras $(38,89 \%)$ de fezes diarréicas e $33(61,11 \%)$ de fezes não diarréicas. Verificou-se um percentual maior de fezes diarréicas positivas $(27,80 \%)$, em relação às não diarréicas positivas $(14,81 \%)$. No período de janeiro a maio de 1993 foram examinadas também seis amostras diarréicas com uma (6,04\%) positiva para Cryptosporidium. As amostras não diarréicas foram em maior número, com 95 (94,06\%) examinadas e $12(11,88 \%)$ positivas.

No período compreendido entre os meses de junho a outubro de 1993 só foi registrado um caso positivo de Criptosporidium em fezes diarréicas.

Tabela 1. Prevalência mensal de $C$. parvum em bezerros lactentes ( 0 a 30dias), procedentes de Bela Vista - Go, durante o período de Janeiro de 1993 a Fevereiro 1994.

\begin{tabular}{|c|c|c|c|c|c|c|c|c|c|}
\hline \multirow[b]{3}{*}{ Meses } & \multicolumn{3}{|c|}{ Amostras de fezes } & \multicolumn{6}{|c|}{ Consistência das fezes } \\
\hline & \multirow[b]{2}{*}{ Examinada } & \multirow{2}{*}{\multicolumn{2}{|c|}{ Positiva }} & \multicolumn{3}{|c|}{ Diarréica } & \multicolumn{3}{|c|}{ Não diarréica } \\
\hline & & & & \multirow{2}{*}{$\frac{\text { Examinada }}{\mathrm{n}}$} & \multicolumn{2}{|c|}{ Positiva } & \multirow{2}{*}{$\frac{\text { Examinada }}{\mathrm{n}}$} & \multicolumn{2}{|c|}{ Positiva } \\
\hline & $\mathrm{n}$ & $\mathrm{n}$ & $\%$ & & $\mathrm{n}$ & $\%$ & & $\mathrm{n}$ & $\%$ \\
\hline 1993 & 7 & 2 & 28,57 & 0 & 0 & 0,0 & 7 & 2 & 28,57 \\
\hline JAN & 11 & 3 & 27,27 & 1 & 1 & 100,0 & 10 & 2 & 20,00 \\
\hline FEV & 17 & 5 & 29,41 & 0 & 0 & 0,0 & 17 & 5 & 29,41 \\
\hline MAR & 29 & 1 & 3,45 & 5 & 0 & 0,0 & 24 & 1 & 4,17 \\
\hline $\mathrm{ABR}$ & 37 & 2 & 5,40 & 0 & 0 & 0,0 & 37 & 2 & 5,40 \\
\hline MAI & 15 & 0 & 0,00 & 0 & 0 & 0,0 & 15 & 0 & 0,00 \\
\hline JUN & 25 & 1 & 4,00 & 3 & 1 & 33,3 & 22 & 0 & 0,00 \\
\hline JUL & 17 & 0 & 0,00 & 3 & 0 & 0,0 & 14 & 0 & 0,00 \\
\hline AGO & 12 & 0 & 0,00 & 3 & 0 & 0,0 & 9 & 0 & 0,00 \\
\hline SET & 10 & 0 & 0,00 & 0 & 0 & 0,0 & 10 & 0 & 0,00 \\
\hline OUT & 9 & 1 & 11,11 & 2 & 0 & 0,0 & 7 & 1 & 14,29 \\
\hline NOV & 15 & 7 & 46,67 & 4 & 4 & 100,0 & 11 & 3 & 29,27 \\
\hline \multicolumn{10}{|l|}{ DEZ } \\
\hline 1994 & 17 & 6 & 35,29 & 9 & 6 & 66,66 & 8 & 0 & 0,0 \\
\hline JAN & 13 & 9 & 69,23 & 6 & 5 & 83,33 & 7 & 4 & 57,14 \\
\hline \multicolumn{10}{|l|}{ FEV } \\
\hline TOTAL & 234 & 37 & 15,81 & 36 & 17 & 47,22 & 198 & 20 & 10,10 \\
\hline
\end{tabular}




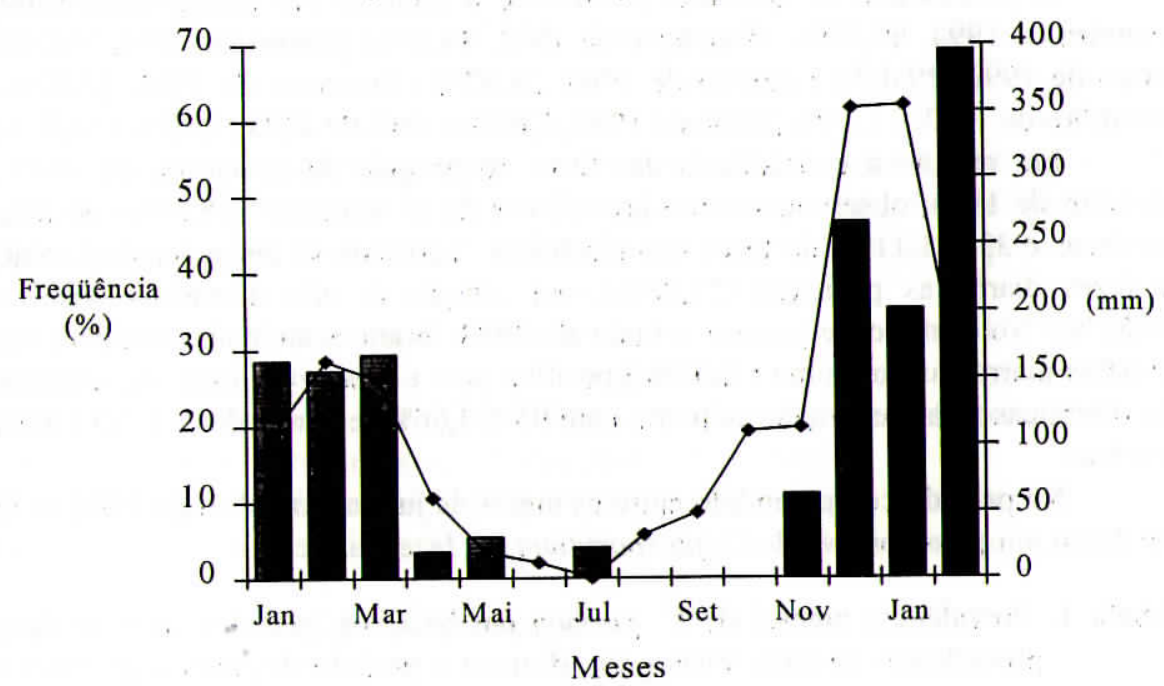

Gráfico 1. Percentuais mensais de oocistos de $C$. parvum em bezerros lactentes $(0$ a 30dias), procedentes de Bela Vista-Go, e valores médios mensais de precipitação pluviométrica da microrregião de Goiânia, durante o período janeiro a dezembro de 1993 e janeiro e fevereiro de 1994.

\section{DISCUSSÃO}

O GRAF. 1 mostra que a precipitação pluviométrica delimitou nitidamente duas estações: uma de baixa precipitação, de março e abril a setembro / outubro e outra das chuvas, entre os meses de outubro e novembro a fevereiro / março.

$\mathrm{Na}$ análise da TAB. 1 e GRAF. 1, verifica-se um maior número de oocistos de Cryptosporidium em bezerros nos meses de janeira a março de 1993 e dezembro de 1993 a fevereiro de 1994. Se compararmos os períodos de novembro de 1993 a fevereiro de 1994 e janeiro de 1993 a março de 1993, que apresentaram os maiores valores percentuais positivos, em relação ao total de amostras colhidas, verifica-se que os correspondentes dos meses de dezembro de 1993 e fevereiro de 1994 alcançaram os maiores índices de ocorrência de Cryptosporidium do que os meses de janeiro a maio de 1993. Essa maior densidade parasitária nos meses referidos parece
CARNEIRO, J.R..;LIMA, J.D. ; RODRIGUES, N. Distribuição eștacional da criptosporidiose em bezerros de Bela Vista-Go. Rev. Pat. Trop.24 ( 2 ): 235 - 241, jul/dez. 1995

estar associada à influência climática, principalmente às chuvas (GRAF. 1). A influência climática associada às infecções pelo Cryptosporidium, já foi relatada por TZIPORI (1988), que relaciona sua maior prevalência aos meses mais quentes e úmidos do ano. Tal fato foi também referido por ARMSTRONG (1987), que relata uma maior freqüência do parasito no verão e durante os meses chuvosos. MATHAN et al. (1985) também consideraram a temperatura e as chuvas como fatores que favoreceram uma maior eliminação de oocistos, e o período seco e frio como o de menor eliminação. A influência da sazonalidade na criptosporidiose bovina foi também confirmada por ANGUS (1988) e por SIEBERT \& GRUNDER (1991), que verificaram uma maior prevalência de oocistos de Cryptosporidium durante os meses mais frios (outubro a março). Porém alguns pesquisadores não comprovaram a influência climática na criptosporidiose, entre eles; ALLEN \& WHITE (1985) e ONGERTH \& STIBBS (1989), todos baseados nas observações de HENRISEN \& KROUGH (1985) de que as infecções pelo Cryptosporidium independem das variáveis chuvas e temperatura como determinantes na criptosporidiose, pois os oocistos já são infectantes logo após sua eliminação nas fezes, o que reforça as observações de HENRIKSEN (1988) de que a criptosporidiose está associada às condições sanitárias precárias e às práticas de manejo deficientes.

A ausência de oocistos nas fezes dos bezerros examinados no mês de junho, segunda quinzena de julho e nos meses de agosto, setembro e outubro de 1993, está provavelmente relacionada a alguns fatores, como dessecação, perda de infectividade dos oocistos e manejo dos animais. Mas segundo ORTOLANI (1988), a resistência dos oocistos de Cryptosporidium é muito grande, pois em temperatura de $4^{\circ} \mathrm{C}$ permanecem viáveis durante meses, enquanto a inibição do seu poder infectante é obtida pela ação do calor ou do frio $\left(65^{\circ} \mathrm{C}\right.$ durante 30 minutos ou $-18^{\circ}$ C por 24 horas). ANDERSON (1986), no entanto, acredita que em intervalos de temperatura entre $18^{\circ} \mathrm{C}$ e $29^{\circ} \mathrm{C}$ há uma perda de infectividade dos oocistos, e HENRIKSEN (1988), inclusive, observou que oocistos eliminados nas fezes e expostos a um período seco reduzem significativamente de 1 a 4 dias a sua infectividade.

\section{CONCLUSÃO}

A criptosporidiose tem uma maior frequêencia durante o período chuvoso e em bezerros com fezes diarréicas da microrregião de Goiânia. 
CARNEIRO, JR ; LIMA, J.D; RODRIGUES, N. Distribuiç̃o estacional da criptosporidiose em bezerros de Bela Vista-Go. Rev. Pat. Trop.24 ( 2 ): 235 - 241, jul/dez. 1995

\section{SUMMARY}

\section{Seasonal distribution of Cryptosporidiosis in calves from Bela Vista-Go}

The seasonal distribution of criptosporidiosis was studied in calves originated from a farm, in the town of Bela-Vista-Go. The months in which Cryptosporidium was most observable were: January to May, 1993, and from December, 1993 to February, 1994. The estimated global prevalence of Cryptosporidium in diarrheic faeces and formed stool was of $15 ; 81 \%$.

KEYWORDS: Seasonal, Cryptosporidium, calves.

\section{REFERÊNCIAS BIBLIOGRÁFICAS}

ALLEN, S. D. ; WHITE, R.D. Incidence of infective agents in Northhern Utah and southeastern Idaho. Agri - Pratice, 6: 23-24, 1985.

ARMSTRONG, M. Cryptosporidiosis. Med. Lab. Sci. 280-284, 1987.

HENRIKSEN, S.A. Epidemiology of cryptosporidiosis in calves. In: ANGUS. K.W.; BLEWETT. D.A. (ed.) Cryptosporidiosis. Proc first Int. Workshop, Edinburg. 79 - 83, 1988.

HENRIKSEN, S.A. ; KROUGH, H.V. Bovine Cryptosporidiosis in Denmark 1 Prevalence, age distribution and seasonal variation. Nord. Vet. Med., 37: 34-41, 1985.

HENRIKSEN, S.A. ; POHLENZ , J. Staining of Cryptosporidia by a modified Ziehl-Neelsen technique. Acta Vet. Scan., 22: 594-596, 1981.

ONGERTH, J.F. ; STIBBS, H. H. Prevalence of Cryptosporidium infection in dairy calves in Western Washington. Am. J. Vet. Res. 50: 1069-1070, 1989.

ORTOLANI, E. L. Padronização da técnica de Ziehl - Neelsen para pesquisa de oocistos de Cryptosporidium: estudo de alguns aspectos epidemiológicos de criptosporidiose em bezerros de rebanhos leiteiros no Estado de São Paulo. São Paulo: Instituto de Ciências Biomédicas da Universidade de São Paulo. 1988, 85 p.(Tese de Doutorado)
CARNEIRO, J.R..;LIMA, J.D. ; RODRIGUES, N. Distribuição estacional da criptosporidiose em bezerros de Bela Vista-Go. Rev. Pat. Trop.24 ( 2 ): 235 - 241, jul/dez. 1995

POHLENZ, J.; MOON, H.W.; CHEVILlE, N.F.; BEMRICK, W.J. Cryptosporidiosis as a probable factor in neonatal diarrhea of calves. J. Am. Vet. Med. Assoc. 172: 452-457, 1978.

SANFORD, S.A. ; JOSEPHSON, G.K.A. Bovine cryptosporidiosis clinical and pathological findings in forty-two scouring neonatal calves. Can. Vet. J. 23: 243247, 1982.

SIEBERT, S.; GRUNDER, H. D. Epidemiological studies of cryptosporidiosis in calves. Tierärztliche Umschav. 46: 202-204, 1991.

TZIPORI, S. Cryptosporidiosis in perspective. Adv. in Parasitol. 27: 63-129, 1988. 